\title{
В.А. Конев
}

\section{УНИВЕРСИТЕТ: ИЗ ГАЛАКТИКИ ГУТЕНБЕРГА В ГАЛАКТИКУ ЦУКЕРБЕРГА}

\begin{abstract}
Культура Просвещения, основанная на печатной книге (галактика Гутенберга), породила университет гумбольдтовского типа. Современная культура, основанная на сетевой логике информационного общества (галактика Цукерберга), требует университет иного типа. Образовательное пространство современного университета включает пространство аудитории и сетевое информационное пространство. Логику действия современного университета определяет приобщение студента к событию мысли, клогике смысла и опыту свободы.

Ключевые слова: культура Просвещения, культура представления, культура присутствия, галактика Гутенберга, галактика Цукерберга, информационное общество, логика смысла, событие мысли.
\end{abstract}

Образование - это своеобразная 3D-печать в культуре, благодаря которой производится / воспроизводится действие, нужное культуре. Тогда университет - это культурный принтер 3D-печати, продуктом которого оказывается породившая его культура. Судьба университета неотделима от судьбы культуры, смысл и содержание его деятельности напрямую задается характером и типом культуры, а его деятельность определяет и укрепляет культуру, его породившую.

Университет, который до сих пор существует, рожден культурой Просвещения. Возникшие еще в XI-XII вв. европейские университеты были качественно другими. Они не только своей структурой сообщества магистров и школяров копировали цеховой (корпоративный) принцип организации профессиональной деятельности в средневековой культуре, но и отвечали на ее запрос - хранить догмы знания и учить, как их истолковать, а не исследовать и не производить новое знание. Культуре Нового времени требовался университет нового типа, который возник как университет гумбольдтовской модели.

Культура modernity, культура Нового времени, возникает в ходе многоходовой культурной революции, утверждающей возрожденческий принцип независимости человека, реформирующей отношение человека и Бога и провозглашающей суверенитет просвещенного разума. Основные особенности новой культуры, пришедшей на смену культуры Средневековья, выражаются в том, что:

- это культура отраслевая, в которой существует разделение труда (мануфактура стала первой формой организации производства в новой культуре производства), в которой наука отделяется от религии и искусства, сама наука становится дисциплинарной, а искусство предстает как система различных видов и т.д.;

- это культура монологичная - в ней звучит один голос, голос разума, который знает истину, и истина для всех одна; 
- это культура рационалистическая - в ней существует строгая последовательность рассуждения, иерархия и субординация идей, дисциплина ума и поведения;

- это культура господства частного интереса, для которого польза (или отношение к пользе) выступает конечным оправданием всякого действия (или его объяснения).

Репрезентантом смыслов культуры Просвещения становится текст, который строится согласно заданным правилам. Поэтому именно с выработки правил начиналась культура Нового времени: законы прямой линейной перспективы Альберти, «Грамматика Пор-Рояля», «Рассуждение о методе» Декарта, «Поэтика» Буало, «Хорошо темперированный клавир» Баха, правила Баррема по бухгалтерскому учету и т.д. Все это было направлено на кодирование как внутренней, так и внешней структуры текста. Возможность такого рода кодирования была укоренена в возникновении и распространении книгопечатания. В методе Гутенберга, который, по мысли Маршалла Маклюэна, автора термина «гутенбергова галактика», внедрял в сознание фиксированную, специализированную точку зрения, а в воспроизводимости и повторяемости видел критерий истины и практическую пользу, брали начало законы галактики Гутенберга, законы новой культуры и рождаемой ею цивилизации [1].

Гравитационное напряжение пространства галактики Гутенберга определялось идеями авторов текстов, которые представляли логику разума, красоту и справедливость мира, нравственные идеалы жизни человека. Поскольку тексты требовали «правильного обращения» с ними, то рядом с автором появилась фигура критика и педагога-наставника, которые, с одной стороны, выясняли и определяли правила существования текста, а с другой - служили посредниками между автором и читателем, направляя чтение и понимание текста. Такой тип культурного существования текста порождал представление о наличии в культуре одной истины, одного идеала, одного правильного поведения. Культура требовала от индивида представления идеала, знания истины и подчинения дисциплине поведения и действия. Это понимание отношения человека и культуры со свойственной научному разуму логикой выразил Томас Гексли в 1862 г.: «Только тот, я думаю, может говорить, что получил образование свободного человека, кто с юности приучил свое тело быть послушным слугой своей воли и в силах легко и с радостью выполнить, как машина, всю работу, на которую он способен; чей ум ясен, холоден, подобен счетному механизму, где все части работают в такт и с одной отдачей; кто готов, словно паровой двигатель, найти себе применение в любой работе...» (цит. по: [1. С. 254]).

Конечно, это идеализированный образ жителя галактики Гутенберга новоевропейской культуры, но он высвечивает культурно-генетический код понимания свободы человеком Просвещения: свобода достигается через знание объективной необходимости. Вот для производства и представления такого знания и создается новый тип университета, в котором обучение органично связано с исследованием, а наряду с библиотекой появляются лаборатории, в котором факультеты перестают делиться на высшие и низшие и начинают отражать реальное дисциплинарное строение науки. 
Отраслевое строение культуры, возникновение дисциплинарной науки потребовало новой структуры университета. Под занавес века Просвещения Иммануил Кант в «Споре факультетов» обосновывает эту новую структуру университета: «Неплохо придумал тот, кто впервые предложил осуществить пришедшую ему в голову мысль поступить со всей совокупностью науки (собственно, с посвятившими себя ей учеными мужами), как на фабрике, по принципу разделения труда, при котором сколько существует отраслей науки, столько же имеется оплачиваемых казной учителей, профессоров, в качестве хранителей этой науки, которые вместе составляют некое ученое сообщество, называемое университетом <...> Университет должен иметь право собственной властью принимать через свои факультеты (небольшие сообщества, образующиеся в соответствии с основными отраслями науки, к которым принадлежат университетские ученые) учащихся $<_{\text {и }}$ т.д.>» [2. C. 46,48$]$.

Конечно, на протяжении двух столетий, прошедших с момента появления первого университета нового типа (Берлинский университет был основан в 1810 г.), гумбольдтовская модель претерпела немало изменений (см. об этом в [3]), но ее сущность сохранялась - университет (или специализированный вуз, который строился по той же модели) оставался центром обучения и производства знаний, а печатная книга, статья в журнале, выпуск дипломированных специалистов и научных сотрудников оставались главными показателями эффективности его работы.

Университет гумбольдтовского типа венчал систему образования, построенную на принципах классно-урочной структуры, где «класс / курс / научная степень» указывали на ступень образования, а «урок / кафедра / факультет» - на содержание передаваемого знания. Он прекрасно справлялся со своими функциями до тех пор, пока культура оставалась культурой представления (сущности истины, идеала и необходимости), но стал давать сбои, когда тип культуры изменился (см. об этом в [4]). Современная европейская культура, утверждающаяся в процессе новой многоходовой культурной революции, начавшейся с провозглашения абсолютной свободы человека (сверхчеловек Ницше, свобода художника эпохи авангарда) и с революции в науке начала XX в., подвергшей ревизии идею единственности истины, меняет своё строение и ориентацию.

Современная культура:

- не строится по отраслевому принципу, это культура, по выражению А. Моля, мозаичная, олицетворением ее строения стал телевизионный экран, на котором могут быть выведены одновременно множество различных программ передач;

- перестала быть монологичной, диалог / полилог, в котором каждый голос провозглашает свою истину, пришел на смену монологу классической культуры и однозначности истины;

- утверждает новую рациональность, в которой случайность играет не менее важную роль, чем обоснованность и необходимость, логика смысла дополняет (заменяет?) логику знания;

- утверждает ценность индивидуальности и значимость действия a recentiori (по ситуации). 
Культура представления мира Просвещения сменяется культурой присутствия, для которой приобретает ценность конкретное действие человека, а не его соответствие идеалам, нормам, методам и т.п. Культура присутствия закрепляет новый утверждающийся экзистенциальный принцип бытия человека, который М.М. Бахтин выразил экзистенциалом «моё не-алиби в бытии»: «Единственность наличного бытия - нудительно обязательна. Этот факт моего не-алиби в бытии, лежащий в основе самого конкретного и единственного долженствования поступка, не узнается и не познается мною, а единственным образом признается и утверждается» [5. С. 112] (курсив Бахтина, выделено полужирным мною. - B.K.). Обратим внимание - не узнается и познается, а признается и утверждается, т.е. моё не-алиби в бытии, моё присутствие не открывается мне кем-то или чем-то (знанием, традицией, правилом), а заявляется и признается. Спустя 80 лет, в 2004 г., в ставшей популярной книге под названием «Производство присутствия» Ханс Ульрих Гумбрехт скажет, что в современной культуре «интерес сместился с опознания значений (с «толкования») к проблемам, связанным с возникновением значения как на конкретно-историческом, так и на метаисторическом уровне» [6. С. 26], где возникновение значения увязывается с определенными ситуациями.

Подвижность и скорость изменения смыслов и содержания различных феноменов современной культуры уже не могут довольствоваться печатной формой предъявления продуктов культуры, производство которой, с одной стороны, задерживает передачу произведения от ее автора к читателю, а с другой - ограничивает круг читателей тиражом печатных экземпляров. Возникновение электронной коммуникации, появление компьютера и разработка различных протоколов передачи данных подготовили почву для рождения новой формы материального существования культуры присутствия. Примечательно, что в самих названиях новых феноменов медиапространства обнаруживает себя семантика присутствия: «...протокол передачи данных - это набор соглашений интерфейса...», сеть «фейсбук». Включение мотива «лица» в этих терминах вряд ли случайно.

Если символом классической культуры Просвещения была печатная книга, то символом современной культуры становится книга лиц - Facebook: фотографии присутствующих лиц на стене моего аккаунта. Человек заявляет о своем присутствии лайками, постами, перепостами, комментариями, изменением своего статуса и любыми другими действиями, свидетельствующими о присутствии в сетевом пространстве. Такой же тип присутствия реализуют и другие многочисленные социальные сети новой галактики, в которой оказался современный человек. Исследования стэндфордского психолога Михала Косински показали, что действия любого человека в социальных сетях Интернета дают возможность создать его психологический портрет. «Для того, чтобы понять человека настолько же хорошо, как и его коллеги по работе, достаточно проанализировать 10 „лайков“, - говорит стэнфордский психолог, - а чтобы узнать его так же хорошо, как муж или жена, нужно около 230-240 ,лайков“. В среднем же „в багаже“ у любого пользователя соцсети есть не менее 300 нажатий на кнопку „нравится“» [7].

Как галактика Гутенберга смогла дать культуре Просвещения адекватное ей пространство, в котором реализовался мир представлений, так галактика 
Цукерберга, создавая новое пространство презентации, требующее непосредственного присутствия действующего индивида, провоцирует новую культуру, которая способна заселить это пространство. Присутствие предъявляет человеку определенные требования. Он должен предъявить или проявить себя - либо открыть свое имя, либо прикрыться маской (в сети - ник, аватар). И в том и в другом случае индивид вступает в зону ответственности, определяемую его собственным поступанием. Смысл этого поступания выразила известная создательница различных перформансов Марина Абрамович своим знаковым перфомансом 1974 г. «Ритм 0»: «Делайте все что угодно с моим телом предложенными предметами - от ножниц до заряженного пистолета». Зритель / участник перформанса оказывается в ситуации испытания его свободы. До каких границ я могу дойти? Это вызов свободы - на что ты решишься! «Человек не должен быть свободным, он обречен на свободу!»заявляет Сартр. Значит, появляется новое отношение к свободе, отношение переживания самой свободы, осмысление того, что значит для человека свобода, что значит для него та новая ситуация, которая не требует долга, а предъявляет ему себя как открытая возможность действия - «Бери от жизни всё!». Это и есть ситуация вызова свободы.

Дать ответ на этот вызов - вот задача новой культуры, которая идет на смену культуры Просвещения. В культуре Просвещения свобода - это ответ на зов необходимости, знание необходимости и действие сообразно с нею были гарантией свободы. Для нового варианта культуры модерна (а мы продолжаем традицию именно культуры Нового времени, которая идею свободы человека взяла у Возрождения), для модерна не в варианте представления, а в варианте присутствия - ответ на вызов свободы укоренен в том опыте свободе, которым владеет человек.

Где и как приобретается опыт свободы? Он приобретается тогда, когда человек ставит свои действия в отношении к пределу, в отношении к преодолению границ как испытанию своих возможностей и способностей. Свобода это напряжение трансгрессии, это способность видеть пределы, к которым устремлены и которыми заряжены твои действия.

Думаю, что смысл работы современного университета и заключается в приобщении студента и преподавателя к опыту свободы. Как это может быть реализовано? Вряд ли можно представить себе некий методический комплекс, который указывал бы на конкретные практики, однозначно ведущие к достижению искомой цели. Ясно, что опыт свободы является не просто личностным опытом, но и опытом глубоко индивидуальным, который приобретается в процессе самой индивидуации. Культивирование способности распознавания индивидуации и понимание ее ценности и должно определять логику действия современного университета и структуру его педагогического пространства.

Условия галактики Цукерберга открывают возможности такой перспективы.

Нынешний университет живет в глобальном информационном пространстве. Гравитационное напряжение этого пространства определяется появлением в нем «ключевых / хэштег» тем / событий, которые требуют к себе отношения. «Лайки» в Facebook или Instagram, «ретвиты» в Twitter - это символы действия в пространстве галактики Цукерберга. Входя в это про- 
странство, человек заявляет о себе, включаясь в образующиеся информационные вихри. Что это значит для университетского действия?

Образовательное пространство современного университета распадается на две части: традиционное пространство аудитории (1) и сетевое информационное пространство (2). Центр тяжести работы с информацией (освоение знаний) переносится (должно переноситься!) в сетевое пространство. Современный преподаватель не должен озвучивать учебный материал (учебник), его дело - создание и размещение в сети учебной информации, которая должна быть оформлена методически грамотно и с использованием ресурсов, предоставляемых Интернетом. Студент работает именно с таким образом оформленной учебной информацией. Причем эта учебная информация может быть подготовлена вовсе не преподавателями того университета, в котором студент числится. И современная сеть уже содержит такого рода материалы (например, MOOC - MassiveOpenOnlineCourse). Совершенно очевидно, что эта тенденция предоставления учебной информации (онлайн-обучение) будет развиваться и со временем станет доминирующей формой. Эта форма деятельности студента университета может работать на культивирование опыта индивидуации (студент может выбирать сам информационные ресурсы, отдавая предпочтения тем или другим источникам), однако ее смысл другой передача необходимых в той или иной профессии знаний.

Подлинная университетская деятельность начинается на пространстве личностного контакта профессора и студента, я бы назвал это пространство не аудиторным, а кафедральным пространством, или пространством вопрошания. Здесь студент не слушает, что ему говорит профессор (аудио), а обращается с вопросами по поводу освоенного материала, здесь идет живое обсуждение возможных смыслов полученной информации, в ходе которого знание становится событием мысли. Знание как событие мысли (М.К. Мамардашвили) перестает быть информацией, раскрывая свои смыслы. Знание в информационном пространстве представлено в логике мышления, а знание как событие мысли в пространстве вопрошания живет в логике смысла (логике с-мысления [8. С. 28]). Поэтому необходимым условием действия в пространстве вопрошания становится овладение логикой смысла (см.: [9-11]), что требует от участников диалога нового отношения к работе с сознанием, направленного на понимание. Ибо «понимать - значит прикасаться к логике то же иначе (так акад. РАН А.В. Смирнов называет логику смысла. - B.K.), осуществлять связность, таящуюся за чешуей значений. Через связность, через работу с ней и через ее явственный показ - выявить логику становления значения; показать, как и почему значение оказывается именно таким, каким оказывается, и что значит „значить“» [8. С. 26]. Идея связности, обнажающая логику смысла, становится очевидной для современной культуры благодаря сетевому пространству. Смысловые вихри галактики Цукерберга, образующиеся на поверхности гипертекстов сетевого пространства, «клиповое мышление», блогосфера, твиттер, чат, эсэмэски, фотографии в Инстаграм - все эти проявления новой электронной галактики основаны на создании связности, на пробуждении смысла. Именно галактика Цукерберга, пришедшая на смену галактике Гутенберга, обнажила различие смысла и значения, мысли и знания, а тем самым и поставила университет перед необходимостью менять 
свою педагогическую ориентацию - учить не знаниям, а умению мыслить, не мышлению, а с-мыслению.

Конечно, такая работа с пониманием знания (умением с-мыслить) осуществлялась и в классическом университете (см.: [12]). Но эта работа была достоянием талантливых педагогов, выдающихся ученых, которые вовлекали отдельных своих воспитанников в науку, это была работа не в пространстве университета, а в пространстве научной школы. Учить мыслить - это было искусством, которым владели и владеют далеко не все педагоги. А сейчас наступило время, когда это искусство должно стать умением, способностью, профессиональным качеством любого университетского (да и не только университетского!) преподавателя.

Как это реализовать в наших отечественных университетах? Это особый и долгий разговор о тех изменениях, которые насущно необходимы, если мы хотим сохранить университетское образование на современном уровне, а тем самым и дать импульс развитию страны и сохранению ее суверенитета.

Я бы хотел закончить свои размышления о предназначении университета в культуре присутствия, которая приходит на смену культуры представления, отсылкой к пониманию задач воспитания, которые сформулировал тот, кто стал провозвестником культуры нового модерна. «Чтобы остаться верным своему характеру, характеру утверждающему <..>, - пишет Фр. Ницше, - я устанавливаю тотчас же три задачи, ради которых нужны воспитатели. Надо научиться смотреть, надо научиться мыслить, надо научиться говорить и писать...» [13. С. 592]. Вряд ли можно согласиться со всем тем, как Ницше интерпретирует каждую из задач, хотя сами эти задачи, несомненно, заслуживают признания. И особенно первая из них. Научиться смотреть! Нельзя не восхититься той прозорливостью, которую обнаруживает философ, предвосхищая возрастание визуальности в культуре XX и нынешнего столетий: кинематограф, телевидение, реклама, плакаты, мода, селфи на любом фоне. Но главное, смотреть - это отнюдь не пялить глаза и всюду всё высматривать. Смотреть - это «охватывать частный случай со всех сторон». Смотреть - это «не реагировать тотчас же на раздражение, а приобрести тормозящие, запирающие инстинкты», «не „хотеть“, мочь откладывать решение» [Там же. C. 593]. Научиться смотреть - это научиться схватывать ситуацию как эту ситуацию, приучить глаз ценить индивидуальное начало в жизни, а тем самым чувствовать и себя личностью и индивидуальностью. Тогда научиться мыслить - это значит видеть нюансы, уметь критически оценить истоки, основания знания, уметь, как выразился философ, «танцевать понятиями, словами». А умение смотреть и умение мыслить не появится без умения говорить и писать! Последнему умению, как ни странно это звучит, университет (а особенно наш современный отечественный) должен учить чуть ли ни в первую очередь!

И если университет выступает в роли 3D-принтера в культуре, то «печатать» в современной культуре он должен индивидуальность мысли (и не только студента!).

\section{Лuтература}

1. Маклюэн М. Галактика Гутенберга / пер. с англ. А. Юдина. Киев : Ника-центр, 2003. 431 с.

2. Кант И. Спор факультетов / пер. с нем. Ц.Г. Арзаканяна, И.Д. Копцева, М.И. Левиной; отв. ред. Л.А. Калинников. Калининград: Изд-во КГУ, 2002. 286 с. 
3. Классический университет в неклассическое время : Труды Томского государственного университета. Серия культурологическая. 2008. Т. 269. 200 с.

4. Ридингс Б. Университет в руинах / пер. с англ. А. Корбута. М. : Изд. дом Гос. университета - Высшая школа экономики, 2010. $304 \mathrm{c}$.

5. Бахтин М.М. К философии поступка / публ. и вступ. заметка С.Г. Бочарова ; примеч. С.С. Аверинцева // Философия и социология науки и техники : ежегодник 1984-1985. М., 1986. C. $80-161$.

6. Гумбрехт Х.У. Производство присутствия: чего не может передать значение. М. : Новое лит. обозрение, 2006. $184 \mathrm{c.}$

7. Интервью М. Косински [Электронный ресурc]. URL: http://tass.ru/opinions/interviews/38855 (дата обращения 01.10.2017).

8. Смирнов А.В. Событие и вещи. М. : ООО «Садра», Изд. Дом ЯСК, 2017. 232 с.

9. Делёз Ж. Логика смысла / пер. с фр. Я.И. Свирского. Москва : Раритет ; Екатеринбург : Деловая книга, 1998. 480 с.

10. Смирнов А.В. Логика смысла: Теория и ее приложение к анализу классической арабской философии и культуры. М. : Языки славянской культуры, 2001. 504 с.

11. Конев В.А. Две концепции логики смысла: Жиль Делёз и Андрей Смирнов. Ч. 1, 2 // Вопросы философии. 2016. № 11. С. 37-47; 2017. № 8. С. 80-88.

12. Петрова Г.И. Ностальгия по классике университета: возможность оправдания и реальность перспективы // Классический университет в неклассическое время : Труды Томского государственного университета. Серия культурологическая. 2008. Т. 269. С. 20-23.

13. Ницие Ф. Сумерки идолов, или Как философствуют молотом // Соч. : в 2 т. Т. 2 / пер. с нем.; сост., ред. и автор примеч. К.А. Свасьян. М., 1990. 829 с.

Vladimir A. Konev, Samara State University (Samara, Russian Federation).

E-mail: vakonev37@mail.ru

Vestnik Tomskogo gosudarstvennogo universiteta. Filosofiya. Sotsiologiya. Politologiya - Tomsk State University Journal of Philosophy, Sociology and Political Science. 2018. 42. pp. 145-153.

DOI: $10.17223 / 1998863 X / 42 / 15$

THE UNIVERSITY: FROM THE GUTENBERG GALAXY TO THE ZUCKERBERG GALAXY

Keywords: Enlightenment culture, presentation culture, presence culture, Gutenberg galaxy, Zuckerberg galaxy, information society, type of university, logic of sense, event of thought.

The article examines how the educational activities of the university changes in the conditions of changing the type of culture. The Enlightenment culture cultivates the right idea (about the world, the purpose of a person, etc.) which gets its expression in the printed text, the Gutenberg galaxy. The Humboldt-type university corresponds to this culture, it crowned the system of education built on the principles of a class-and-lesson structure, where the "class/course/academic degree" indicated the level of education, and the "lesson/department/faculty" indicated the content of the transferred knowledge. The Humboldt university coped well with its functions as long as culture remained a culture of representation (the essence of truth, ideal and necessity), but it began to malfunction when the type of culture changed. Modern culture is a mosaic culture; it is a culture of dialogue in which each voice proclaims its truth; it is a culture of new rationality, including the chance (aleatory culture); it is a culture of affirming the value of the individual principle and the significance of the action a recentiori (depending on a situation). Modern culture is the culture of presence rather than representation; a symbol of its acts is not a printed book, but a book of persons - Facebook, the Zuckerberg galaxy. The Zuckerberg galaxy and the information society demonstrate the diversity and personal meaning of information. The distinction between meaning and sense, thought and knowledge was exposed, and thus the university faced the need to change its pedagogical orientation - to teach the ability to work with diverse information, to teach to think, not to teach knowledge, to teach to understand (the logic of sense), not to teach thinking. Modern culture based on the network logic of the information society needs a different type of university. The educational space of the modern university is divided into two parts: (1) the traditional lecture hall space, and (2) the network information space. The logic of the action of the modern university should be determined by familiarizing students to the event of thought, to the logic of sense and to the experience of freedom. 


\section{References}

1. McLuhan, H.M. (2003) Galaktika Gutenberga [The Gutenberg Galaxy]. Translated from English by A. Yudin. Kyiv: Nika-tsentr.

2. Kant, I. (2002) Spor fakul'tetov [The Dispute of the Faculties]. Translated from German by Ts.G. Arzakanyan, I.D. Koptsev, M.I. Levina. Kaliningrad: Kaliningrad State University.

3. Balandin, M.N. (ed.) (2007) Klassicheskiy universitet v neklassicheskoe vremya: Trudy Tomskogo gosudarstvennogo universiteta [Classical University in Non-Classical Time: Proceedings of Tomsk State University]. Vol. 269. Tomsk: Tomsk State University.

4. Readings, B. (2010) Universitet v ruinakh [The University in Ruins]. Translated from English by A. Korbut. Moscow: HSE.

5. Bakhtin, M.M. (1986) K filosofii postupka [To philosophy of the act]. In: Frolov, I. (ed.) Filosofiya i sotsiologiya nauki i tekhniki. Ezhegodnik 1984-1985 [Philosophy and Sociology of Science and Technology]. Moscow: Nauka. pp. 80-161.

6. Gumbrecht, H.Y. (2006) Proizvodstvo prisutstviya: chego ne mozhet peredat' znachenie [Production of Presence: What Meaning Cannot Convey]. Translated from English by S. Zenkin. Moscow: Novoe literaturnoe obozrenie.

7. Kosinski, M. (n.d.) Interv'yu M. Kosinski [Interview with M. Kosinski]. [Online] Available from: http://tass.ru/opinions/inter-views/38855. (Accessed: 1st October 2017).

8. Smirnov, A.V. (2017) Sobytie i veshchi [Event and Things]. Moscow: Sadra.

9. Deleuze, G. (1998) Logika smysla [Logic of Sense].Translated from French by Ya.I. Svirsky. Moscow: Raritet; Ekaterinburg: Delovaya kniga.

10. Smirnov, A.V. (2001) Logika smysla. Teoriya i ee prilozhenie $k$ analizu klassicheskoy arabskoy filosofii i kul'tury [Logic of Sense. Theory and Its Application in the Analysis of Classical Arabic Philosophy and Culture]. Moscow: Yazyki slavyanskoy kul'tury.

11. Konev, V.A. (2016) Dve kontseptsii logiki smysla: Zhil' Delez i Andrey Smirnov [Two Concepts of the Logic of Sense: Gilles Deleuze and Andrey Smirnov]. Voprosy filosofii. 11. pp. 37-47.

12. Petrova, G.I. (2007) Nostal'giya po klassike universiteta: vozmozhnost' opravdaniya i real'nost' perspektivy [Nostalgia for the university's classics: the possibility of justifying and perspective]. In: Balandin, M.N. (ed.) (2007) Klassicheskiy universitet v neklassicheskoe vremya: Trudy Tomskogo gosudarstvennogo universiteta [Classical University in Non-Classical Time: Proceedings of Tomsk State University]. Vol. 269. Tomsk: Tomsk State University. pp. 20-23.

13. Nietzsche, F. (1990) Sochineniya $v 2 t$. [Works in 2 vols]. Vol. 2. Translated from German by K.A. Svasyan. Moscow: Mysl'. 